\title{
Karakteristik dan Ciri-ciri Fundamentalisme sebagai Aliran dan Gerakan Keagamaan
}

\author{
Yusak Tridarmanto•dan Djaka Soetapa**
}

The two writers of the article below describe the characteristics of fundamentalism as a school and a movement of religion. Some of them are as a moral movement to return to fundamental truth in the uncertainty of society life, back to the tenet of Holy Scripture that never denies as a guidance of daily life. In this sense, it has similarities to orthodoxy but the differences how to apply the truth of Holy Book in society. The fundamentalism believes the coming of the Thousand Year Kingdom. It does not hesitate to confront and isolate the sinning people who are not in accordance with belief norms, the fundamentalists believe that they are guided saved people, while the people are not in their group go astray. The fundamentalism movement in the beginning is sporadic individual not organize, it involves in the political domain. The writers declare that the elements of fundamentalism that mentioned above there are in every group of fundamentalism, the particular elements exist in one group whereas the other elements emerge in the other group. At least, the essence of the fundamentalism movement as effort to refer the pure doctrine to protect many kinds of fundamentalism.

\section{Beberapa Catatan Historis}

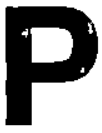

ada perempat terakhir abad ke 19 di kalangan para pemimpin agama Kristen Protestan di Amerika banyak yang menyadari bahwa mereka telah memasuki zaman yang semakin maju yang ditandai oleh kemajuan pesat di bidang ilmu pengatahuan dan tehnologi. Serentak dengan itu timbul suatu kebutuhan hakiki dalam kehidupan beragama mereka yakni perlunya tetap menghadirkan nilai-nilai keagamaan mereka di tengahtengah zaman yang modern seperti itu. Untuk itu perlu adanya upaya "penyesuaian" nilai-nilai tradisional keagamaan mereka dengan zaman yang baru di mana mereka berada. Namun upaya mereka ternyata tidak berjalan mulus, sebab mereka meng- hadapi reaksi yang sangat keras dari pihakpihak tertentu di kalangan agama Kristen Protestan tersebut. Reaksi keras ini nampak dalam hal bahwa mereka yang terlibat di dalam upaya "menyesuaikan" doktrin-doktrin fundamental Kristen dengan arus perkembangan zaman modern tersebut dikecam sebagai "bidat" atau "penyesat". Untuk menghadapi gerakangerakan "bidat" atau "sesat" ini mereka juga melakukan gerakan-gerakan menentang dengan cara "mempertahankan doktrin-

-Staf Pengajar pada Fakultas Theologia, UKDW, Yogyakarta.

"Ketua Pusat Studi Agama-Agama (PSAA), Fakultas Theologia, UKDW, Yogyakarta. 
Topik: Karakteristik dan Ciri-ciri Fundamentalisme..., Yusak Tridarmanto dan Djaka Soetapa

doktrin tradisional seperti itu dari berbagai macam upaya penyesuaian". ${ }^{1}$ Untuk itu mereka menerbitkan serial karangan yang salah satu di antaranya yang dianggap paling penting ialah serial berjudul "The Fundamentals". Serial ini diterbitkan antara tahun 1910-1915 di Amereka Serikat dengan menggunakan nama tersebut disertai maksud untuk menunjukkan adanya dasar-dasar fundamental Kekristenan yang sedang terancam oleh berbagai upaya "penyesuaian". Dari latar belakang seperti inilah nampaknya istilah Fundamentalisme muncul, dan menjadi semakin populer ketika pada tahun 1920 ketika seorang editor dari surat kabar The Watchman. Examiner bernama Curtis Lee Laws menulis: "Seorang fundamentalis adalah seorang yang bersedia 'bertempur secara terbuka' ataupun berdebat dengan gigihnya untuk membela unsur-unsur fundamental dari iman Kristen". Dalam pada itu istilah Fundamentals dipakai dengan makna ganda, yakni sebagai suatu deskripsi atas unsurunsur fundamental iman, dan sekaligus ajakan untuk berjuang dengan gigih untuk mempertahankan unsur-unsur fundamental tersebut.

Dalam perkembangannya, modernisme memang menjadi fakta kehidupan yang tidak mungkin lagi dapat dibendung. Demikian pula reaksi terhadpnya juga tidak pernah berhenti, bahkan berkembang ke arah yang semakin kompleks sesuai dengan situasi sosio-religious, bahkan sosioekonomi-politik di mana istilah tersebut dipakai. Bahkan pemakaiannyapu tidak lagi terbatas hanya di kalangan orang-orang Kristen Protestan, tetapi merambah pula ke berbagai agama yang ada di dunia ini, bahkan dikenakan pula kepada gerakangerakan sosial politik non-religious. Dengan demikian maka Fundamentalisme bukanlah phenomenon masa lampau saja seperti ketika pertama kali muncul, namun sebenarnya juga merupakan phenomenon modern saat ini. ${ }^{2}$ Namun justru karena itu upaya untuk memberikan pemahaman yang lebih akurat dan konklusif terhadap pokok masalah Fundamentalisme menjadj sangat sulit bahkan mustahil.

Anehnya dalam kehidupan kini, istilah tersebut sering dipakai tanpa ada penjelasan apapun tentangnya, seakan-akan masyaräkat luas telah dengan sendirinya mengetahui makna yang terkandung di dalamnya. Memang pada umumnya istilah tersebut lebih banyak dimaknai secara negatif dari pada positifnya. Negatif karena istilah Fundamentalisme sering dimaknai sebagai suatu paham yang meneritang terhadap segala bentuk modernisasi yang semakin mengglobal sebagai akibat dari kemajuan ilmu pengetahuan dan tekhnologi. Karena latar belakang historis munculnya istilah ini memang berasal dari suatu tradisi keagaman tertentu seperti terurai di atas, maka banyak kalangan dewasa ini yang mengungkapkan sikap negatif mereka dengan memaknai fundamentalisme sebagai paham yang "menyalah-gunakan" dasar-dasar kepercayaan agamis" sematamata untuk menentang segala bentuk kehidupan kemasyarakatan yang dirasa bertentangan dengan kaidah dasar keyakinan agamis mereka. ${ }^{3}$ Walaupun

'Lebih lanjut baca Martin E. Marty and R. Scott Appleby (Eds.), Fundamentalisms Observed Vol. I. (Chicago: The University of Chicago Press, 1994) khususnya p.1-66.

${ }^{2}$ Martin E. Marty ad R. Scott Appleby (Eds.), Fundamentalisms Comprehended Vol 5 (Chicago: The University of Chicago Press, 1995) p.259-276.

'Secara lebih mendalam pokok masalah ini dapat dibaca di dalam buku Religious Fundamentalism: An Asian Perspective (Bangalore: South Asia Theological Research Institute, 1993 ed. by John S. Augus-tine) p. $1 \mathrm{ff}$. 
demikian, terlepas dari kenyataan bahwa secara teknis istilah fundamentalisme ini telah dimaknai secara negatif, secara lebih' obyektif masih perlu dikaji ulang akan kebenaran klaim tersebut. Mengingat kompleksitas permasalahan yang ada, maka yang dapat dilakukan hanyalah mencoba memberikan gambaran diskriptif tentang karakter dan ciri-ciri gerakan tersebut. Dari gambaran inilah maka para pembaca diharapkan dapat lebih memahami apa Fundamentalisme itu. Tentu saja ciri khas dan karakter ini akan berbeda dari satu agama ke agama yang lain, sesuai dengan corak perkembangannya masing-masing. Sementara itu tidak mungkin dalam kesempatan ini menguraikan setiap ciri khas dari Fundamentalisme dari setiap agama yang ada. Namun karena munculnya paham ini pertama-tama dari kalangan Protestan, uraian ini akan lebih banyak bertumipu pada ciri khas dan kharakter Fundamentalisme yang berkembang di dalam Protestantisme.

\section{Beberapa Ciri Khas dan Karakter Fundamentalisme}

1. Muncul sebagai gerakan moral untuk kembali kepada apa yang mereka yakini sebagai kebenaran-kebenaran fundamental di tengah-tengah kehidupan masyarakat yang tidak menentu

Umumnya daerah-daerah Urban merupakan lahan yang subur bagi tumbuh dan berkembangnya paham Fundamentalisme. Bertemunya unsur masyarakat dari berbagai macam lapisan serta latar belakang yang berbeda; baik dalam hal suku, agama, budaya, dan pendidikan; semakin merebaknya berbagai macam pabrik sebagai tanda berlangsungnya proses industrialisasi; semakin terbukanya arus informasi dari berbagai macam penjuru dan berbagai macam jenis; 'semakin berkembangnya ilmu pengetahuan dan technologi; dan semakin ketatnya persaingan pencari kerja, sering menjadikan situasi kehidupan masyarakat menjadi kian tidak menentu. Norma dan nilai kehidupan yang semula dipegangi dalam rangka menjalani hidup bersama masyarakat sering menjadi goyah karenanya. Bahkan tidak mustahil bahwa nilai-nilai kehidupan yang semula dijunjung tinggi sekarang diacuhkan. Masyarakat seolah kehilangan pedoman dalam menjalani kehidupan bermasyarakatnya sehari-hari. Muncullah berbagai macam persoalan k'emasyarakatan sebagai akibat dari proses terjadinya degradasi moral.

Dalam kondisi kehidupan masyarakat yang tidak menentu seperti itulah maka muncullah gerakan-gerakan reaksioner yang ingin mengedepankan kembali nilainilai kebenaran yang dianggap telah dilupakan atau bahkan telah hilang dari perjalanan hidup sehari-hari. Semua ini dimaksudkan untuk mengembalikan kondisi kehidupan yang tidak menentu itu ke dalam kondisi ideal yang mereka idam-idamkan. Umum-nya nilai-nilai kebenaran yang ingin mereka kedepankan kembali itu bersumber pada tradisi keagamaan tertentu. Dalam arti yang demikian, maka sebenarnya Fundamentalisme merupakan gerakan pembaharuan moral. Namun karena pada akhirnya istilah Fundamentalisme ini dikenakan tidak terbatas hanya dalam bingkai kehidupan agamis saja, tetapi ke arena yang lebih luas, maka nilai-nilai kebenaran inipun juga bisa bertumpu pada sumber-sumber lain, seperti sejarah, pandangan filsafat, adat istiadat dan sebagainya.

2. Kembali kepada pegangan hidup sehari-hari yakni Kitab Suci yang mereka percayai tidak pernah salah

Dalam rangka menemukan kembali nilai-nilai kebenaran fundamental, kaum Fundamentalis kembali kepada pegangan 
Topik: Karakteristik dan Ciri-ciri Fundamentalisme..., Yusak Tridarmanto dan Djaka Soetapa

hidup mereka sehari-hari yakni Kitab Suci. Namun bukan kembalinya kepada Kitab Suci itu sendiri yang membuat sifat khas dari kaum Faundamentalis, melainkan justru kepercayaan mereka terhadap Kitab Suci sebagai yang tidak pernah salah itulah yang khas. Kitab Suci tidak pernah salah karena "diwahyukan" oleh Allah, dan oleh sebab itu di dalamnya tidak terdapat kesalahan sedikitpun, baik dalam hal teologi, sejarah, geographi, ataupun ilmu pengetahuan yang terkandung di dalamnya. Mereka menolak semua bentuk studi kritis terhadap Kitab Suci kalau pada akhirnya hanya dipakai untuk mempersoalkan kebenaran berita Kitab Suci itu sendiri. Temuan-temuan baru di dalam ilmu pengetahuan tidak boleh dipakai untuk membuktikan kebenaran-kebenaran Kitab Suci. Sebaliknya semua fakta kehidupan masyarakat justru harus diperoleh dari upaya mengumpulkan petunjuk-petunjuk dari Kitab Suci dan selanjutnya semua temuan ilmu pengetahuan harus disesuaikan dengan fakta-fakta kebenaran Kitab Suci tersebut. Jadi yang harus menjadi satusatunya sumber kebenaran bukanlah ilmu pengetahuan, tetapi sebaliknya Kitab Suci.

Karena diwahyukan oleh Allah, maka Kitab Suci bersifat otoritatif dan segala hal yang terkandung di dalamnya harus diwujudnyatakan di dalam kehidupan kini. Bahkan semua aturan kehidupan serta nilainilai kemasyarakatan harus senantiasa diterangi oleh Kitab Suci. Segala hal yang dirasa bertentangan dengan nilai-nilai kebenaran Kitab Suci harus dilawan. Kepercayaan terhadap "ketidak-salahan" Kitab Suci seperti inilah yang selanjutnya menjiwai seluruh proses penafsiran Kitab Suci. Semua bentuk penafsiran Kitab Suci akan ditolak manakala proses penafsiran itu mengandung kritik dan pertanyaan-pertanyaan yang sifatnya meragukan kebenaran Kitab Suci. Dengan prinsip hermeneutis seperti ini maka kaum Fundamentalis cenderung memahami Kitab Suci mereka secara hurufiah, betapapun juga tidak selamanya harus hurufiah saja. Apabila masalahnya telah secara jelas dan tegas dinyatakan di dalam Kitab Suci, maka itu harus dilaksanakan apa adanya sesuai dengan yang tertulis di dalam Kitab Suci tersebut. Namun apabila masalahnya kurang atau bahkan tidak jelas, maka itu harus ditafsirkan dengan cara mencari jawabannya di dalam bagian-bagian dan kitab-kitab yang lain dari Kitab Suci tersebut. Dengan kata lain, apabila terdapat kekurang atau ketidak jelasan dari ayat-ayat tertentu, maka harus diupayakan penjelasannya dengan "mengharmonisasikan" dengan bagian kitab-kitab yang lain di dalam Kitab Suci tersebut. Akibatnya, kaum Fundamentalis cenderung kurang terbuka dan bersikap kaku terhadap penafsiran-penafsiran baru yang muncul dan berkembang seiring dengan perkembangan zaman.

\section{Memiliki kesamaan namun berbeda dengan ortodoksi}

Dalam memperjuangkan diwujudnyatakannya kembali nilai-nilai kebenaran Kitab Suci dalam kehidupan sehari-hari, kaum Fundamentalis melakukannya dengan penuh kesadaran. Sadar terutama akan munculnya kekuatan demonis di tengahtengah kehidupan ini yang ditandai oleh semakin merajalelanya berbagai macam tindakan amoral dan semakin terdesaknya kebenaran-kebenaran fundamental. Karena itu dengan penuh kesadaran pula mereka ingin memulihkan kembali kehidupan yang telah dicengkeram oleh kuasa demonis itu kembali ke dalam suasana hidup dikuasai oleh kebenaran-kebenaran ilahi yang bersumber pada Kitab Suci. Mereka menolak semua bentuk kompromi antara nilai-nilai kebenaran Kitab Suci dengan nilai-nilai 
zaman. Untuk itu nilai-nilai kebenaran Kitab Suci harus ditegakkan kembali. Dalam hal inilah maka kaum Fundamentalis memiliki kesamaan dengan kaum ortodoks. Bedanya terletak dalam hal bahwa kaum ortodoks mewujudkan semua nilai-nilai kebenaran Kitab Suci di tengah-tengah masyarakat yang sebagian besar, kalau tidak semuanya, mendukung niat tersebut. Dengan kata lain mereka mewujud-nyatakan nilai-nilai kebenaran Kitab Suci tersebut di tengahtengah sistem kemasyarakatan yang stabil. Sebaliknya kaum Fundamentalis berjuang menegakkan kembali nilai-nilai kebenaran tersebut di tengah-tengah kehidupan masyarakat yang tidak menentu, di mana sebagian besar, kalau tidak semuanya, anggota masyarakat telah meninggalkan dan bahkan tidak peduli lagi terhadap nilainilai kebenaran Kitab Suci tersebut. Clifford Geertz menyebut perbedaan ini dengan sebutan "dikuasai oleh kepercayan akan kebanaran-kebenaran Kitab Suci", yakni kaum ortodoksi, dengan "memegangi atau menguasai kebenaran-kebenaran Kitab Suci" yakni kaum Fundamentalis. ${ }^{4}$

\section{Percaya pada akan segera datangnya zaman yang baru (Kerajaan Seribu Tahun)}

Dalam menegakkan perjuangannya, kaum Faundamentalis sangat mempercayai akan segera datangnya zaman yang baru, zaman yang akan ditetapkan sendiri oleh Allah. Di kalangan kekristenan zaman ini sering disebut dengan istilah Kerajaan Seribu Tahun. Semua ini tidak terlepas dari upaya mereka untuk senantiasa belajar memaknai sejarah di bawah terang Kitab Suci mereka, di samping juga belajar dari Kitab Suci mereka tentang apa yang kelak akan terjadi dengan dunia ini di masa depan, yakni di zaman akhir.
Mereka percaya akan segera datangnya Kerajaan Seribu Tahun, serta apa yang akan terjadi ketika Kerajaan Seribu Tahun itu benar-benar tiba. Ketika saatnya tiba, maka akan terjadi penghakiman kosmis, di mana dunia ini akan dijadikan dua kelompok; yakni kelompok yang akan diikut sertakan masuk ke dalam Kerajaan Seribu Tahun dan kelompok yang tidak akan disertakan masuk ke dalam Kerajaan Seribu Tahun. Orang-orang yang tetap berpegang pada kebenaran-kebenaran Kitab Suci akan diikutsertakan di dalam Kerajaan Seribu Tahun sedangkan mereka yang tidak berpegang pada kebenarn tersebut akan ditinggalkan. Pada zaman akhir orangorang beriman akan mendengar tiupan suara terompet surgawi, dan ketika itulah mereka semua akan diangkat masuk ke dalam surga dan meninggalkan mereka yang tidak beriman. Kepercayaan ini akan menjadi dasar-dasar pertimbaingan etis untuk bertindak di dalam kehidupan ini. Bahkan tidak mustahil mereka akan menjadi sangat berani dan rela mati sekalipun demi Kerajaan Seribu Tahun ini.

Datangnya Kerajaan Seribu Tahun ini dipercayai terjadi sewaktu-waktu tanpa diketahui secara pasti oleh siapapun. Karena itu yang terpenting bagi manusia yang hidup di dunia ini ialah berjaga-jaga. Dalam rangka mempersiapkan manusia menyongsong datangnya Kerajaan Seribu Tahur inilah kaum Fundamentalis melakukan kegiatan-kegiatan keagamaan dalam bentuk pewartaan kepada berbagai pihak. Dalam rangka itu pula mereka mencoba mempelajari Kitab Suci dengan tujuan menemukan nubuat-nubuat mengenái apa yang akan terjadi menjelang datangnya

${ }^{4}$ Clifford Geertz, Islam Observed (Chicago: University of Chicago Press, 1968) p.17 seperti dikutip di dalam Martin E. Marty, Fundamentalism Observed, p.14. 
Kerajaan Seribu Tahun. Peristiwa-peristiwa mengerikan akan terjadi terlebih dahulu sebelum Kerajaan Seribu Tahun itu benarbenar tiba. Ini terjadi sebagai akibat dari pekerjaan kuasa kegelapan. Namun pada akhirnya akan diakhiri oleh peperangan besar antara kuasa kegelapan dengan kuasa Allah, di mana kuasa kegelapan itu akan dihancurkan-Nya. Semua orang akan menderita ketika itu, namun orang-orang yang beriman akan diselamatkan dari penderitaan yang mengerikan tersebut, dan sebaliknya mereka yang tidak beriman akan dibiarkan menderita.

\section{Bersifat separatis}

Berdasar pada pandangan teologis mereka, kaum Fundamentalis menegakkan disiplin rohani yang begitu ketat terhadap para anggotanya. Banyak di antara mereka yang menolak untuk berdansa, tidak minum minuman keras ataupun merokok, menentang segala bentuk perjudian dan segala macam bentuk kemaksiatan. Dalam hubungan dengan sesama mereka juga seringkali tidak begitu gampang menerima pihak-pihak lain, termasuk mereka yang mengklaim diri sebagai orang beriman, kecuali apabila mereka benar-benar'dapat hidup sesuai dengan aturan disiplin rohani mereka. Banyak pihak dicurigai 'sebagi pihak yang telah ternoda oleh kehidupan murtad sebagi akibat kompromi kehidupan selama ada di dunia ini. Ketika kaum Fundamental harus berhadapan dengan orangorang yang tidak percaya, dan mereka percayai sebagai orang-orang berdosa seperti nampak di dalam perilaku kehidupan mereka yang tidak seturut dengan norma iman mereka, mereka tidak segansegan berkonfrontasi dan memisahkan diri dari mereka. Dari antara saudara-saudara sekeluargapun kaum Fundamentalis juga tidak segan-segan memisahkan diri manakala mereka menemukan alasan yang sama.
Itu semua mereka lakukan agar mereka pada akhirnya tidak terbuang dari anugerah berada di dalam Kerajaan Seribu Tahun. Pendek kata kaum Fundamentalis lebih suka memilih kehilangan saudara-saudara sekandung sekalipun, bahkan kehilangan ayah dan ibunya, dari pada harus kehilangan kesempatan untuk berada di dalam Kerajaan Seribu Tahun.

\section{Sangat menekankan dan menonjol- kan pentingnya pewartaan untuk pertobatan}

Kaum Fundamentalis mempercayai sepenuhnya bahwa mereka ádalah orangorang yang telah diselamatkan sementara orang-orang lain di luar mereka, mereka pandang sebagai orang-orang yang tidak atau belum diselamatkan. Dengan keyakinan seperti itu dunia ini seakan-akan terbagi menjadi dua bagian besar yakni dunia orang-orang yang telah diselamatkan dan dunia orang-orang yang belum atau tidak diselamatkan; dunia kudus, dan dunia kejahatan; dunia terang dan dunia kegelapan. Sebagai yang telah diselamatkan, mereka menyadari sepenuhnya panggilan untuk membagikan pengalaman hidup mereka sebagai orang-orang yang telah diselamatkan, dengan cara mewartakan warta keselamatan itu kepada pihak lain dengan satu tujuan yakni agar mereka yang menerima pewartaan itu kelak bertobat dan diselamatkan pula. Karena dijiwai oleh sikap kurang terbuka, maka dalam pewartaan itu mereka sepenuhnya menempatkan diri sebagai subyek sedangkan mereka yang diberi warta menjadi obyek semata-mata. Demikian pula untuk mencapai tujuan pewartaan ini mereka menggunakan segala daya, dana, dan sarana seita cenderung kurang sensitif terhadap tatanan kehidupan kemasyarakatan yang ada. Seolah-olah tidak ada pikiran lain di dalam benak mereka kecuali kehendak agar para 
Topik: Karakteristik dan Ciri-ciri Fundamentalisme..., Yusak Tridarmanto dan Djaka Soetapa

penerima warta bertobat dan menjadi penganut agama mereka. Mereka menyiarkan berita-berita pewartaan mereka melalui radio, televisi, pamflet-pamflet, kaset, dan bahkan tidak segan-segan datang dari rumah ke rumah dengan satu tujuan meyakinkan pihak lain bahwa tidak ada jalan masuk ke surga kecuali jalan yang mereka tunjukkan. Dengan posisi seperti ini maka mereka cenderung bersifat eksklusive, dan tentu saja kurang atau bahkan tidak dapat menerima pikiran-pikiran yang bernada inklusive.

\section{Awalnya berfungsi sebagai gerakan yang bersifat sporadis individual}

Awalnya Fundamenlatisme bukanlah suatu gerakan yang terorganisir di dalam suatu struktur organisasi tertentu. Begitu pula sesuai dengan esensi dasarnya sebagai gerakan pembaharu, maka suarasuara pembaharuan itu lebih banyak disuarakan secara individual tanpa secara langsung terkait dengan suara-suara senada lainnya yang ada. Selaras dengan tujuan memberikan suara pembaharuan ini pula, maka awalnya gerakan ini merupakan gerakan intra institusi, artinya gerakangerakan yang muncul di dalam lingkungan suatu kehidupan bersama tertentu, katakanlah Gereja X misainya, dan demi kehidupan bersama itu pula, yakni demi Gereja $X$ itu pula. Namun dari kenyataan bahwa suara-suara mereka sering membentur dinding yang keras, maka muncullah kemudian kesadaran mengkoordinasikan suara-suara mereka di dalam suatu struktur organisasi tertentu. Dengan demikian gerakan ini menjadi gerakan yang berada di luar kehidupan bersama yang semula menjadi target suara pembaharuan tersebut. Akibatnya, sasaran suara merekapun juga menjadi semakin luas, tidak lagi terbatas pada kehidupan bersama yang semula menjadi target suara mereka, namun kepada target sasaran yang lebih luas.

\section{Terlibat juga di dalam kegiatan- kegiatan sosial politik}

Seiring dengan target sasaran yang lebih luas, yang tidak lagi terbatas hanya pada sasaran-sasaran keagamaan saja, maka kaum Fundamentalis juga mengarahkan sasaran kritiknya kepada masalahmasalah sosial politik. Di Amerika Serikat misalnya, kaum Fundamentalis ini terlibat secara aktif melawan teori Evolusi Charles Darwin pada tahun 1920-an. Bahkan mereka juga secara gigih terlibat di dalam gerakan anti komunisme yang membayangi kehidupan masyarakat pada masa tahun 1950an. Pada saat terjadi krisis ekonomi pada tahun 1930-an di Amerika Serikat, kaum Fundamentalis menganggap bahwa krisis itu disebabkan pertama kali oleh karena krisis spiritual. Gejolak-gejolak kemasyarakatan yang terjadi ketika itu dimengerti sebagai tanda-tanda akan segera datangnya Kerajaan Seribu Tahun, di mana Anti Kristus mulai bekerja. Secara politis para elit Yahudi ketika itu telah dituduh sebagai yang memainkan peran demonik.

Dalam berjuang di tengah-tengah situasi kehidupan yang tidak menentu seperti itu, kaum Fundamentalis seringkali juga sangat peduli terhadap issue-issue krusial seperti misalnya perlunya mempertahankan unit terkecil masyarakat, yakni keluarga, dari berbagai macam distorsi seperti perceraian, perselingkuhan, penyalah gunaan anak (child abuse), seks bebas, aborsi dan sebagainya. Dalam rangka ini pula seringkali mereka lebih condong kepada sistem pembagian kerja antara laki-laki dan perempuan, di mana laki-laki bekerja di luar rumah untuk mencukupi segala kebutuhan keluarga, sementara istri tinggal di rumah 
Topik: Karakteristik dan Ciri-ciri Fundamentalisme..., Yusak Tridarmanto dan Djaka Soetapa

bertanggung jawab pada tanggung jawabtanggung jawab domestik. Dalam perjuangan itu tidak menutup kemungkinan bahwa mereka menjadi gerakan-gerakan yang radikal, tanpa kompromi sifatnya. ${ }^{5}$

\section{Catatan Akhir}

Sekali lagi perlu ditegaskan bahwa uraian di atas bertumpu pertama-tama pada Fundamentalisme yang tumbuh dan berkembang di dalam Kekristenan. Tentu tidak setiap unsur yang disebutkan di atas senantiasa ada pada setiap kelompok Fundamentalisme. Bisa saja unsur-unsur tertentu ada pada kelompok yang satu, namun tidak ada pada kelompok yang lain. Mengingat bahwa pada setiap agama terdapat juga kelompok-kelompok fundamentalisme ini, maka sudah barang tentu akan terdapat ciri-ciri dan karakternya masingmasing. Namun tidak mustahil bahwa prinsipprinsip dasar dari kaum Fundamentalisme seperti terurai di atas juga akan hadir di sana, betapapun bertumpu dari tradisi keagamaan yang berbeda pula. Paling tidak esensi dasar gerakan kaum Fundamental sebagai upaya "pemurnian ajaran", dengan kembali kepada kebenaran-kebenaran fundamental yang dipegangi tetap akan menjadi payung besar yang memayungi berbagai macam corak dan bentuk Fundamentalisme.

\section{Beberapa Buku Acuan}

Augustine, John S., 1993, Religious Fundamentalism: An Asian Perspective (Bangalore: South Asia Theological Research institute. ed. by John S. Augustine) p.1ff.

Barr, James. 1981. Fundamentalism. London: SCM Press.

Clifford, Geertz. 1968. Islam Observed Chicago: University of Chicago Press. Marty, Martin E. and Appleby, R. Scott (Eds.), 1994. Fundamentalisms Observed Vol. I, Chicago: The University of Chicago Press. khususnya p.1-66. Marty, Martin E. and R. Scott Appleby (Eds.), 1995, Fundamentalisms Comprehended Vol. 5 Chicago: The University of Chicago Press, p. 259-276.

5Lihat Martin E. Marty, Fundamentalisms Obeserved, p.44-45. 